\title{
Effect of interstimulus interval and heterogeneity of difference on same-different judgments of visual patterns
}

\author{
LESTER E. KRUEGER and RONALD G. SHAPIRO \\ Ohio State University, Columbus, Ohio
}

\begin{abstract}
Subjects judged whether two single lines or matrices of slashes, separated by an interstimulus interval (ISI) ranging from .25 to $3 \mathrm{sec}$, were identical or different. A long ISI, by increasing internal noise, was expected to produce more spurious mismatches than matches and thus prompt more rechecking of different pairs. However, with a long ISI the fast-same effect was eliminated, whereas false-different errors abounded. The data were fitted by a model that permitted inertia in adjusting the criterion for rechecking. However, intermixing (vs. blocking) trials on ISI in Experiment 2 , which ought to have retarded criterion adjustment, did not further reduce the rechecking of spurious mismatches. Consistent with the noisy-operator theory, increasing the heterogeneity of difference (external noise) in Experiments 3 and 4 increased false-same errors.
\end{abstract}

When people must decide whether two displays are identical or not, same judgments typically are faster than different judgments, especially if the two displays are presented sequentially, so that the encoding of the first display may facilitate or prime that of the second (Proctor, 1981). When the interstimulus interval (ISI) between the two displays is increased beyond the .5-sec value typically used, however, same response time (RT) may suffer. When the ISI between two tones increased from 1 to $10 \mathrm{sec}$, Bindra, Williams, and Wise (1965) found that both $\mathrm{RT}$ and errors increased more on same than on different pairs. Mitchell (1972) found that as the ISI between two numerals or nonsense shapes increased from .5 to $6 \mathrm{sec}$, the speed advantage for same pairs remained constant, whereas the preponderance of false-different responses (i.e., errors on same pairs) increased, especially on unnamed forms.

The present study, which varied the ISI from .25 to $3 \mathrm{sec}$, attempted to replicate the latter effects and to determine whether they are due to inertia in adjusting the criterion for rechecking. According to the noisy-operator theory (Krueger, 1978), the increase in internal noise with a long ISI ought to produce more spurious mismatches. If the criterion for rechecking is not adjusted accordingly, too much rechecking will be devoted to quite small perceived differences, thus increasing the same RT as well

This study was supported by National Institutes of Health Grant HD09282. Experiment 1 was conducted as a master's thesis by Ronald G. Shapiro under the supervision of Lester E. Krueger. We are grateful to Steve Kelso for assistance in collecting the data and to Mark H. Chignell, Kenneth R. Paap, and Robert W. Proctor for helpful comments on previous versions of this report. Ronald G. Shapiro is now at Dunlap and Associates East, Inc., 17 Washington Street, Norwalk, CT 06854. Requests for reprints should be sent to Lester E. Krueger, Human Performance Center, Ohio State University, 404-B West 17th Avenue, Columbus, OH 43210. as the number of undetected spurious mismatches (falsedifferent responses). Krueger (1985) varied the distance from fixation $\left(0.5^{\circ}, 2^{\circ}\right)$ of a simultaneously presented letter pair and found that greater criterion inertia occurred when difficult and easy trials were intermixed rather than presented in separate blocks of trials. To test this possibility on ISI, trials in Experiment 2 were blocked by ISI on one session for each subject, but were intermixed by ISI on another session.

The present study used nonverbal stimuli, because letters might undergo little memory loss over the ISIs used here and might permit priming to occur (Proctor, 1981), thereby speeding the same response. Displays on different pairs always differed in size, however, so subjects might have used verbal labels ("small," "large") on some comparisons. In Experiments 1 and 2, matrices of slashes were presented. In Experiments 3 and 4, single lines were presented, and the heterogeneity of difference (external noise) also was varied.

\section{EXPERIMENTS 1 AND 2}

\footnotetext{
Method

Subjects. Twelve Ohio State University undergraduates participated in Experiment 1 and 16 in Experiment 2 in order to receive course credit. All had at least 20/30 (corrected) vision as tested with a Snellen chart. Data were excluded on eight additional Experiment 2 subjects whose errors exceeded $10 \%$.

Apparatus. Displays were presented at a $60-\mathrm{Hz}$ refresh rate and at $32-\mathrm{cd} / \mathrm{m}^{2}$ intensity on a fast-decay P31 phosphor by an Imlac PDS-4 graphics computer. Each subject sat alone in a dark room, with the head held fast in a chinrest located $70 \mathrm{~cm}$ from the display screen.

Stimulus materials. Each slash, /, was $.03 \mathrm{~cm}$ wide and $.23 \mathrm{~cm}$ long. Five or 11 slashes were distributed randomly over an imaginary $4 \times$ 4 matrix $\left[.90 \mathrm{~cm}\left(.74^{\circ}\right)\right.$ high $\times .75 \mathrm{~cm}\left(.61^{\circ}\right)$ wide], except that at least $40 \%$ of the slashes had to fall in the top, bottom, left, and right halves of the matrix. On same pairs, each display contained the same number of slashes (5 or 11) and in the same matrix positions. On different pairs,
} 
one display contained 5 slashes and the other contained 11 (the same 5 slashes and an additional 6 slashes).

In Experiment 1, each subject participated in four sessions held on 4 successive days. All 352 (32 practice, 320 regular) trials presented on each day had the same ISI. In Experiment 2, each subject participated in two sessions (blocked, intermixed). In the blocked session, there were four blocks ( 8 practice, 80 regular trials each), one for each ISI $(.25, .5,1$, and $3 \mathrm{sec})$. As in Experiment 1 , each ISI was used first, second, third, or fourth for an equal number of subjects. In the intermixed session, each of the 11 (1 practice, 10 regular) successive sets of 32 trials contained 8 trials for each ISI. Half of the subjects had the blocked session first, and the other half had it second.

Each 32-trial set contained 8 each of 5-5 and 11-11 same pairs and 5-11 and 11-5 different pairs. Trials were ordered randomly, except that no more than 3 same or 3 different pairs could occur in immediate succession. Two different random orderings of trials and random patterns of slashes were used in Experiment 1, and six (four blocked, two intermixed) in Experiment 2.

To begin each trial, the subject pressed a footpedal. The fixation dot then appeared alone for $1 \mathrm{sec}$, followed by the first pattern of slashes for $50 \mathrm{msec}$, the fixation dot alone for $.25, .5,1$, or $3 \mathrm{sec}$, the second pattern of slashes for $50 \mathrm{msec}$, and finally the fixation dot alone until the subject responded, after which feedback on response accuracy appeared for $2 \mathrm{sec}$.

Half of the subjects pressed a right-hand button for same judgments and a left-hand button for different judgments, and the other half had the reverse hand assignment. Trials having an RT above $3 \mathrm{sec}$ or below $200 \mathrm{msec}$ were discarded. Mean RT was computed for correct trials only.

\section{Results}

As shown in Figure 1, RT was lower on same (vs. different $)$ pairs $[\mathrm{F}(1,26)=10.97, \mathrm{p}<.01]$, whereas errors were higher $[\mathrm{F}(1,26)=16.07, \mathrm{p}<.001]$. Increasing the ISI increased both $\mathrm{RT}[\mathrm{F}(3,78)=34.53, \mathrm{p}<$ $.001]$ and errors $[F(3,78)=26.43, p<.001]$. Trial type interacted with ISI on both RT $[\mathrm{F}(3,78)=19.54, \mathrm{p}<$ $.001]$ and errors $[F(3,78)=13.83, p<.001]$. As ISI increased, the fast-same effect decreased, whereas the preponderance of false-different responses increased. In separate analyses at each ISI, same judgments were sig-

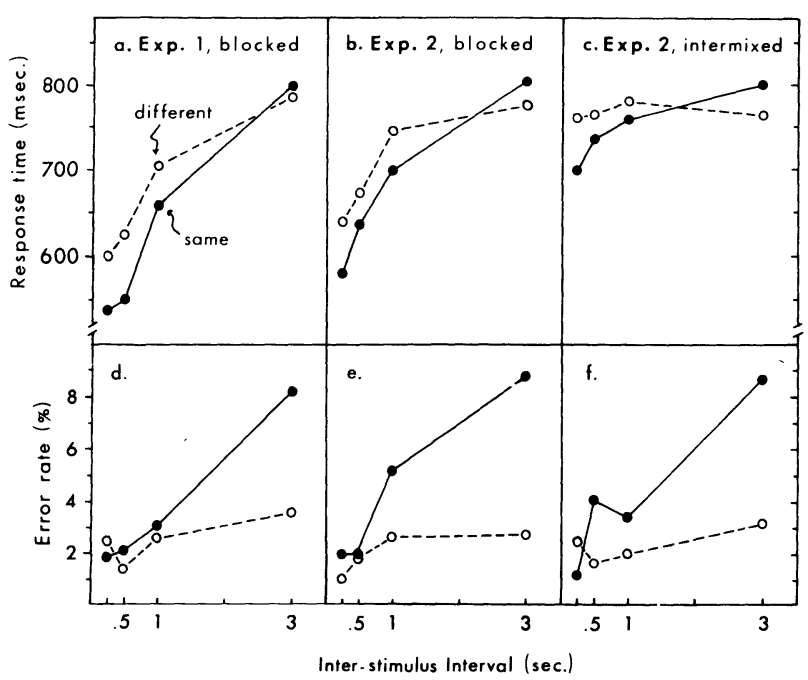

Figure 1. Experiments 1 and 2: Mean RT and percentage of error rate by trial type, interstimulus interval, and blocking versus intermixing of trials on interstimulus interval. nificantly faster at ISIs of $.25, .5$, and $1 \mathrm{sec}(\mathrm{p}<.01$ or better in all cases) and, to a marginally significant extent, slower at an ISI of $3 \sec [F(1,26)=3.86, p=.06]$; errors were significantly higher on same pairs at ISIs of $.5 \sec (\mathrm{p}<.05)$ and $3 \sec (\mathrm{p}<.001)$.

In Experiment 2, the RT and error patterns did not differ between the blocked and intermixed conditions. Judgments were significantly faster on blocked than on intermixed sessions $[F(1,14)=7.62, p<.025]$, especially when the ISI was short $[\mathrm{F}(3,42)=9.79, \mathrm{p}<.001]$ (see Figure 1).

Judgments were faster if the first display contained 5 slashes. Thus, 5-5 trials were faster than 11-11 trials $[\mathrm{F}(1,26)=6.78, \mathrm{p}<.025]$, and 5-11 trials were faster than $11-5$ trials $[\mathrm{F}(1,26)=18.73, \mathrm{p}<.001]$, especially when the ISI was long $[\mathrm{F}(1,26)=5.55, \mathrm{p}<.01]$ (see Figure 2 below).

A second analysis considered trial type on the two preceding trials, if correct. There was a 34-msec advantage on RT in having a same (vs. different) Trial $\mathrm{n}-1$ $[\mathrm{F}(1,26)=11.60, \mathrm{p}<.01]$ and a 16-msec advantage in having a same Trial $n-2[\mathrm{~F}(1,26)=18.31, \mathrm{p}<.001]$.

\section{Discussion}

As the ISI lengthened, internal noise increased, but, just as Bindra, Williams, and Wise (1965) and Mitchell (1972) had found, rechecking faltered, so the preponderance of false-different errors increased, whereas the fast-same effect decreased and reversed. Memory decay may have prevented rechecking as ISI increased, but errors were relatively low, reaching only $8 \%$ at the 3 -sec ISI. More likely, rechecking faltered because of criterion inertia, which would explain the crossover on RT as ISI increased, although the speed advantage for different at the 3-sec ISI was only marginally significant $(p=.06)$. No increase in rechecking failure was evident when ISI was intermixed, perhaps because rechecking failure was maximal when ISI was blocked.

Criterion-inertia model. Krueger (1978, Case 1), who assumed properly adjusted rechecking, predicted the general pattern of faster RT and higher error rate on same pairs in Experiment 1, but not the change with ISI. Therefore, a criterion-inertia model was fitted to the data. Also tested was whether internal noise is equally likely to add or delete features (Krueger, 1978; Massaro \& Schmuller, 1975) or is more likely to delete features (Proctor \& Rao, 1983b; Shapiro \& Krueger, 1983). A separate, independent random-walk process (Kinchla \& Smyzer, 1967) was posited at each of the 16 matrix positions of the first display during each temporal interval (rehearsal pass) of $250 \mathrm{msec}$, fluctuating between two states (slash present, absent). The duration of comparison (see Krueger, 1978, Appendix A) also was set at $250 \mathrm{msec}$, and likelihood ratios were computed for each ISI separately (i.e., no criterion inertia), and for the four ISIs combined (i.e., full inertia). A base error rate was added to allow for motor confusions, and, as in Krueger's (1978) Case 1 , the deadline was set at five passes.

As shown in Figure 2, the model captured the main trends in the data. For both predicted (lines) and observed (circles) data, the RT disparity on same vs. different decreased and then reversed as ISI increased, whereas the error disparity steadily increased. The estimated parameter values were as follows. On each rehearsal pass, the probability of feature (slash) deletion, .009 , exceeded that of feature addition, .006 , which accounts for the lower RT found when the first display contained 5 slashes. A 5-slash display, having fewer features to lose than an 11slash display, would change less over the ISI, thus making it more similar to an identical second display and more distinct from a different one. However, errors were not lower for 5-first pairs, and the 5-first condition may have been faster not because feature loss exceeded feature gain, but because less time was needed to compare a smaller first display with the second display. 


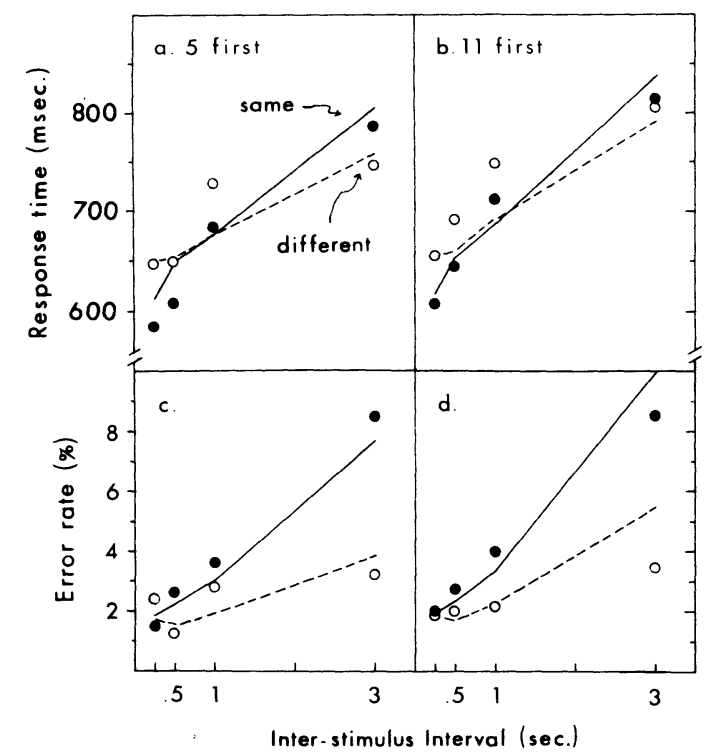

Figure 2. Experiments 1 and 2: Predicted (lines) and observed (circles) mean RT and percentage of error rate by size of first pattern (5 or 11 slashes). (Same trials: filled circles and unbroken lines; different trials: open circles and broken lines.)

On each comparison pass, the probability was 0.1 that a feature mismatch would change to a match, or vice versa. A common (full-inertia) criterion was used on $55 \%$ of the decisions. The base time on RT was $340 \mathrm{msec}$, and the base error rate was $1.30 \%$.

\section{EXPERIMENTS 3 and 4}

In Experiments 3 and 4, each display was a single vertical line rather than a pattern of slashes, and trials were always blocked by ISI. Unidimensional stimuli, such as single lines and tones, typically produce faster different RT (Bindra, Donderi, \& Nishisato, 1968; Bindra, Williams, \& Wise, 1965), apparently because of the presence of external noise or heterogeneity of difference (Krueger, 1979). The first line in a pair may be larger or smaller than the second, so the distribution of perceived differences on different trials would overlap that on same trials from two directions, thus producing rechecking on many same trials as well as many false-same errors (Krueger, 1979). The latter effects ought to dissipate as ISI increases, however, because increased internal noise favors the opposite RT and error disparities.

In Experiment 3 (constant difference), the difference ratio between the two lines on different pairs was kept fixed for a particular subject, except that it could be positive or negative. In Experiment 4 (variable difference), the difference ratio varied across trials, thus introducing additional external noise.

\section{Method}

There were 30 subjects in Experiment 3 (constant difference) and 26 in Experiment 4 (variable difference).

The method was the same as in Experiments 1 and 2, except for the following changes. Each member of a pair was a single vertical line of $.25, .5,1$, or $2 \mathrm{~cm}\left(.20^{\circ}, .41^{\circ}, .82^{\circ}\right.$, or $\left.1.64^{\circ}\right)$, presented for
$100 \mathrm{msec}$. The lower end of each line was displaced randomly upward by $0, .08, .17$, or $.34 \mathrm{~cm}$, so that a change in the level of the upper end would not provide a reliable cue to a change in length.

There were four blocks of trials, one for each ISI. Each block contained 10 practice and 80 ( 40 same, 40 different $)$ regular trials. The order of the ISIs was $1, .25,3$, and $.5 \mathrm{sec}$ for half of the subjects, and .5 , $3, .25$, and $1 \mathrm{sec}$ for the other half. The second line was longer than the first line on half of the different pairs, and shorter on the other half. In Experiment 3 (constant difference), 10 subjects each saw only the .5and $1-\mathrm{cm}$ lines (1:2 ratio), only the .5 - and $2-\mathrm{cm}$ lines (1:4 ratio), or only the 1- and 2-cm lines (1:2 ratio). Because performance did not differ for the three subgroups, their data were combined. In Experiment 4 (variable difference), the two lines in a pair differed by ratios of $1: 2,1: 4$, and $1: 8$, respectively, on 20,10 , and 10 of the 40 different trials in each block. Two different random orderings of trials were used in each experiment.

\section{Results}

As shown in Figure 3, RT was lower in Experiment 3 (constant difference) than in Experiment 4 (variable difference) $[F(1,54)=4.17, p<.05]$, as were errors $[F(1,54)=6.98, \mathrm{p}<.025]$. The shortest $(.25-\mathrm{cm})$ line was not used in Experiment 3, which may explain the better performance in that experiment. In Experiment 4, RT on different trials decreased as the difference ratio increased $[F(2,50)=18.51, p<.001]$, as did errors $[F(2,50)=64.00, p<.001]$. For difference ratios of $1: 2,1: 4$, and $1: 8$, RTs were 856,779 , and $805 \mathrm{msec}$, respectively, whereas errors were $15.72 \%, 4.93 \%$, and $4.40 \%$.

Same pairs were slightly, but not significantly, faster than different pairs $[\mathrm{F}(1,54)=1.35]$, and were more accurate to a marginally significant extent $[F(1,54)=3.79$, $\mathrm{p}<.06]$. Experiment 4 tended to produce faster but less accurate different trials. The greater excess of errors on different trials in Experiment 4 (vs. Experiment 3) was significant, $2.02 \%$ versus $0.03 \%[\mathrm{~F}(1,54)=4.03, \mathrm{p}<$

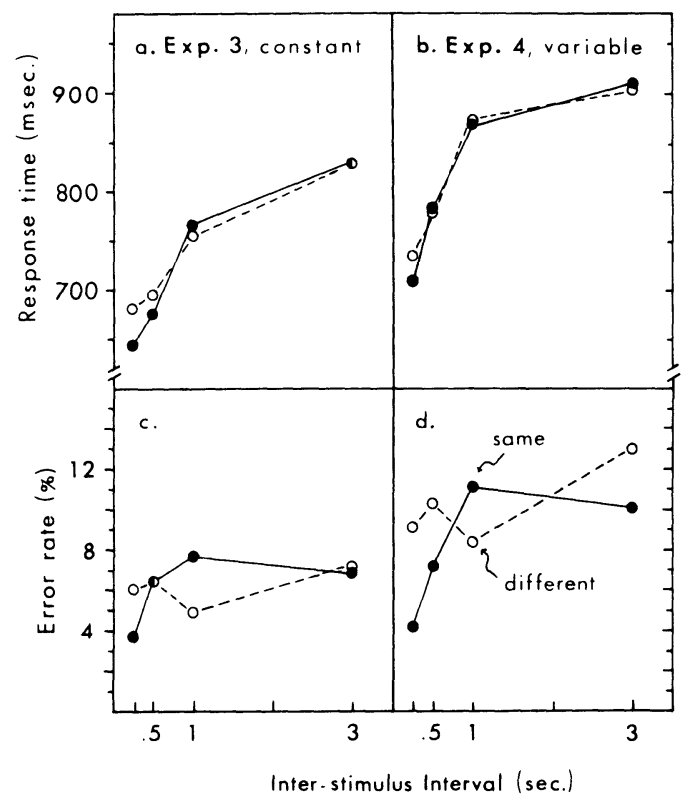

Figure 3. Experiments 3 (constant difference) and 4 (variable difference): Mean RT and percentage of error rate by trial type and interstimulus interval. 
$.05]$, but the smaller speed advantage for same pairs was not, 5 versus $12 \mathrm{msec}(\mathrm{F}<1)$.

Increasing the ISI increased both RT $[\mathrm{F}(3,162)=$ 43.92, $\mathrm{p}<.001]$ and errors $[\mathrm{F}(3,162)=6.30, \mathrm{p}<$ $.001]$. The ISI $\times$ trial type interaction was significant on errors $[F(3,162)=6.46, p<.001]$ and marginally significant on $\mathrm{RT}[\mathrm{F}(3,162)=2.38, \mathrm{p}<.08]$. As ISI increased, RT and errors increased more rapidly on same (vs. different) trials, although on errors this trend reversed at the 3-sec ISI (see Figure 3). In separate analyses at each ISI, same pairs were significantly faster and more accurate at the .25 -sec ISI ( $p<.01$ in both cases) and significantly less accurate at the $1-\sec$ ISI $(p<.01)$.

A second analysis considered trial type on the two preceding trials, if correct. Having a same (vs. different) Trial $n-1$ produced a 43-msec advantage on $R T[F(1,54)$ $=58.31, \mathrm{p}<.001]$ and a $2.54 \%$ advantage on errors $[F(1,54)=24.76, p<.001]$. Having a same Trial $n-2$ produced a 10-msec advantage on $\operatorname{RT}[\mathrm{F}(1,54)=5.76$, $\mathrm{p}<.025]$ and a $1.93 \%$ advantage on errors $[\mathrm{F}(1,54)=$ $13.57, \mathrm{p}<.001]$. Preceding different pairs seemingly left more refractoriness in their wake because of the greater complexity of their memory traces, not greater difficulty of processing (Krueger \& Shapiro, 1981), since $\mathrm{RT}$ and errors were about equal for current (Trial n) same and different pairs. In the second analysis, unlike the first, the ISI $\times$ Trial $\mathrm{n}$ type interaction was fully significant on both $\mathrm{RT}[\mathrm{F}(3,162)=4.47, \mathrm{p}<.025]$ and errors $[\mathrm{F}(3,162)=5.80, \mathrm{p}<.001]$. The fast-same effect was $34,20,2$, and $-18 \mathrm{msec}$ for ISIs of $.25, .5,1$, and $3 \mathrm{sec}$, respectively, whereas the excesses of errors on different trials were $3.94 \%, 1.08 \%,-2.90 \%$, and $1.38 \%$.

\section{Discussion}

In Experiments 3 and 4, as in Experiments 1 and 2, RT and errors tended to increase more on same than on different trials as ISI increased, although the trend was somewhat erratic on errors. Owing to the increased level of internal noise, the same RT fared better here than in the typical unidimensional study (Krueger, 1979). Even so, the external noise introduced by the unidimensional stimuli (single lines) largely neutralized the RT and error tendencies of internal noise, virtually eliminating the fast-same effect and producing a marginally significant excess of false-same errors. When additional external noise was introduced in Experiment 4, the tendency for false-same errors to predominate significantly increased, and the speed advantage for same pairs decreased slightly, but not significantly. Proctor and Rao (1983a), on the other hand, found only a slight and insignificant decrease in the tendency for same trials to be faster but less accurate when they increased external noise by replacing a homogeneous set of letters with a heterogeneous set. Letters may differ relatively little in discriminability, however, whereas the difference ratio on line length varied four-fold (i.e., from 1:2 to 1:8) in Experiment 4.

\section{REFERENCES}

Bindra, D., Donderi, D. C., \& Nishisato, S. (1968). Decision latencies of "same" and "different" judgments. Perception \& Psychophysics, 3, 121-130.

BindRa, D., Williams, J. A., \& Wise, J. S. (1965). Judgments of sameness and difference: Experiments on decision time. Science, 150, 1625-1627. (Erratum, p. 1699)

KinChla, R. A., \& SMYZER, F. (1967). A diffusion model of perceptual memory. Perception \& Psychophysics, 2, 219-229.

Krueger, L. E. (1978). A theory of perceptual matching. Psychological Review, 85, 278-304.

KRUEGER, L. E. (1979). A model of unidimensional perceptual matching. Journal of Experimental Psychology: Human Perception and Performance, 5, 277-288.

KRUEGER, L. E. (1985). Effect of intermixed foveal and parafoveal presentation on same-different judgments: Evidence for a criterioninertia model. Manuscript submitted for publication.

KRUEGER, L. E., \& SHAPIRO, R. G. (1981). Intertrial effects of samedifferent judgements. Quarterly Journal of Experimental Psychology, 33A, 241-265.

Massaro, D. W., \& Schmuller, J. (1975). Visual features, preperceptual storage, and processing time in reading. In D. W. Massaro (Ed.), Understanding language: An information-processing analysis of speech perception, reading, and psycholinguistics (pp. 207-239). New York: Academic Press.

MitCHELL, D. C. (1972). Short-term visual memory and pattern masking. Quarterly Journal of Experimental Psychology, 24, 394-405.

Proctor, R. W. (1981). A unified theory for matching-task phenomena. Psychological Review, 88, 291-326.

Proctor, R. W., \& RAO, K. V. (1983a). Null effects of exposure duration and heterogeneity of difference on the same-different disparity in letter matching. Perception \& Psychophysics, 33, 163-171.

Proctor, R. W., \& RAO, K. V. (1983b). Reinstating the original principles of Proctor's unified theory for matching-task phenomena: An evaluation of Krueger and Shapiro's reformulation. Psychological Review, 90, 21-37.

SHAPIRo, R. G., \& KRUEGER, L. E. (1983). Effect of similarity of surround on target letter processing. Journal of Experimental Psychology: Human Perception and Performance, 9, 547-559.

(Revision received for publication December 7, 1984.) 